\title{
Effect of physical activity on body condition in Swedish companion dogs
}

\author{
Sara Ringmark, Emma Björk, Anna Jansson \\ From Animal Obesity - causes, consequences and comparative aspects \\ Uppsala, Sweden. 14-16 June 2015
}

\section{Introduction}

Obesity is believed to be an increasing health and welfare problem among companion dogs. In general, obesity is the result of imbalanced energy intake and utilisation, i.e. too much feed in relation to level of physical activity.

\section{Objectives}

The aim of this study was to assess body condition among Swedish companion dogs and to study if it could be associated with type and amount of exercise performed.

\section{Material and methods}

Body condition score (BCS, scale 1-9) was assessed in 102 companion dogs (inclusion criteria 1-10 years, max $120 \mathrm{~min} /$ week of activities in addition to walks) and owners were interviewed about daily time of walks, activity level of the dog during walks (Low: mostly walk, Medium: trot and some running, High: running) and of additional activities (yes/no). Statistical analysis were performed using a mixed model including age ( $\leq 5$ years/ $>5$ years) activity level and additional activity as fixed effects and minutes of walk/day as a continuous variable. Effects were considered significant at $\mathrm{p}<0.05$ and values are presented as lsmeans $\pm \mathrm{SE}$.

\section{Results}

Thirty dogs (29\%) had a BCS $\geq 6$ and accordingly described as fat or obese. The BCS decreased as the level of activity during daily walks increased (Low $5.7 \pm$ 0.3 , Medium $4.7 \pm 0.2$, High $3.3 \pm 0.3, \mathrm{p}<0.0001)$ and BCS was also lower in dogs performing additional activities $(3.9 \pm 0.3$ vs. $5.2 \pm 0.2)$. Minutes of walks/day did not affect BCS.

\footnotetext{
* Correspondence: sara.ringmark@slu.se

Department of Animal Nutrition and Management, Swedish University of Agricultural Science, Uppsala, Sweden
}

Submit your next manuscript to BioMed Central and take full advantage of:

- Convenient online submission

- Thorough peer review

- No space constraints or color figure charges

- Immediate publication on acceptance

- Inclusion in PubMed, CAS, Scopus and Google Scholar

- Research which is freely available for redistribution 